\title{
Exploring boot camps for 'gatekeeper' service courses in mathematics
}

\author{
Author: \\ Anita Campbell \\ Affiliation: \\ ${ }^{1}$ Academic Support \\ Programme for Engineering \\ in Cape Town (ASPECT), \\ University of Cape Town, \\ South Africa \\ Correspondence to: \\ Anita Campbell \\ Email: \\ anita.campbell@uct.ac.za \\ Postal address: \\ Private Bag X3, Rondebosch \\ 7701, South Africa \\ Dates: \\ Received: 15 Apr. 2015 \\ Accepted: 03 Sept. 2015 \\ Published: 24 Nov. 2015 \\ How to cite this article: \\ Campbell, A. (2015). \\ Exploring boot camps for \\ 'gatekeeper' service courses \\ in mathematics. Pythagoras, \\ 36(2), Art. \#298, 9 pages. \\ http://dx.doi.org/10.4102/ \\ pythagoras.v36i2.298

\section{Copyright:} \\ (c) 2015. The Authors. \\ Licensee: AOSIS \\ OpenJournals. This work is \\ licensed under the Creative \\ Commons Attribution \\ License.
}

Pressure to increase the throughput of university students in ethical ways has been a catalyst for innovations to improve learning and student success. Student dropout occurs mostly in the first year of study and poor performance is a major contributor to dropout even if the underlying reason for the poor performance is not academic under-preparedness. This article discusses the design and implementation of a mathematics tutored reassessment programme (TRP or 'boot camp') to improve the pass rate of students writing supplementary examinations for first year engineering mathematics. Interviews with students and tutors suggest that the TRP cultivated positive affective changes in students. A notable result from this case study was that students who qualified for a reassessment with marks in the range $40 \%-44 \%$ (and who would not normally have been granted a supplementary examination) outperformed students qualifying with marks of $45 \%-49 \%$, for whom attendance at the TRP was optional. Theoretical motivations for five principles guiding the design of the TRP are discussed.

\section{Introduction}

The knowledge economy strategy used in many countries has put pressure on universities to produce more graduates as a way to stimulate economic growth (Deiaco, Hughes \& McKelvey, 2012). Low graduation rates of students in the South African higher education institutions (Council on Higher Education, 2013) suggest that improving throughput rates is necessary, rather than just increasing the number of students accessing higher education. Strategies to help students pass their service courses timeously are an important part of the goal to improve student throughput at university.

A service course is a compulsory or optional course offered by a department in which students will not take their major courses. The first year mathematics courses for engineering students considered in this case study are examples of service courses. In these first year mathematics courses, students are taught fundamental concepts in calculus and other topics that are directly or indirectly relevant to many courses in their engineering degrees. Compulsory service courses perform a 'gatekeeper' role: students cannot graduate without passing the service courses. Although these courses are not the focus of the degree, students who cannot meet the demands of the service course are assumed to be less likely to meet the demands of further courses. This assumption reflects research findings (e.g. Van Eeden, De Beer \& Coetzee, 2001) that past academic performance is the strongest indicator of future academic success. However, the placement of service courses in the early stages of a degree programme means that student achievement in these courses is likely to be impacted by factors such as how well and quickly students 'acculturalise' to a higher education institution (Race, 2014) and not only their capacity to succeed in higher education.

Numerous studies (e.g. Kuh, Kinzie, Buckley, Bridges \& Hayek, 2006; Tinto, 2012) point to practices that can ease the transition from school to university for students, such as integrating support services and engaging students through active learning techniques. However, as noted by Pym and Paxton (2013), the problem of adjusting to university is exacerbated for first-generation students, particularly if they are experiencing an English-only learning environment for the first time. Catching up after falling behind in studies is especially difficult in courses that have a final examination after one semester.

The aim of this case study is to show how a tutored reassessment programme (TRP or 'boot camp') can be implemented to improve student success in 'gatekeeper' service courses. The article begins with the history of the development of the mathematics TRP for service courses in engineering mathematics and a description of the design used at a university in the Western Cape, South Africa, for the July 2014 and January 2015 programmes. A discussion of some of the tensions regarding the notion of student success is followed by the impact theory of the programme and 
five theory-based principles that underpin the current design. Students' results following the supplementary examinations in July 2014 and January 2015 are presented and discussed.

\section{Development of the mathematics tutored reassessment programme}

The Department of Chemical Engineering at the university has a long-established academic development focus, with two full-time academic development lecturers (Case et al., 2015; Heydenrych \& Case, in press). One of this department's successful initiatives to increase student throughput was boot camps for courses with low pass rates (Case, Von Blottnitz, Fraser, Heydenrych \& Petersen, 2013). During vacations, students would have two to three weeks of intense review of a course, led by a senior tutor. Typically the senior tutor would be a postgraduate student with recent tutoring experience in the course. The senior tutor would prepare the review material in consultation with the lecturer. The lecturer would be responsible for setting and marking the examination, which would be unseen by the senior tutor to prevent 'teaching to the test'. The lecturer's involvement would be minimal to preserve their research time. Final pass marks would be recorded as $50 \%$ on students' academic transcripts to prevent the boot camp being strategically used as a means to increase their overall mark average, since students who passed the course did not have an opportunity to improve their marks.

The success of the boot camps in Chemical Engineering led to this model being adapted for use in the service courses considered in this case study, Engineering Mathematics $1 \mathrm{~A}$ and $1 \mathrm{~B}$, which are semesterised courses for engineering students with final examinations in June and November and supplementary examinations in July and January, respectively. Pilot programmes for the Engineering Mathematics courses were run in July 2013 and January 2014 and an external review of the January 2014 programme (Chapman, 2014) influenced the design of the mathematics TRP used in July 2014 and January 2015.

The TRP consisted of five days of intense revision in the week prior to the supplementary examinations. The schedule was the same for each of the five days of contact session: in the morning a review lecture by an experienced lecturer was followed by whiteboard tutorials, where 24 to 28 students worked in self-formed groups of two to five students around large wheel-mounted whiteboards spaced around a large room with movable furniture. While students wrote their answers to worksheet questions on the whiteboards, two or three tutors (senior or postgraduate students with recent tutoring experience in the course) walked between groups, offering advice, questioning students and providing help when students were stuck. Interaction between students was encouraged by having answers displayed openly on the whiteboards. Compared to tutorials where students record answers on paper while sitting at desks, the use of whiteboards stimulated more questioning between students and also between tutors and students. After a lunch break,

\begin{tabular}{|c|c|}
\hline 09:00-11:00 & Review lecture \\
\hline $11: 00-13: 00$ & $\begin{array}{l}\text { Whiteboard tutorial session in which students work in } \\
\text { groups around large, movable whiteboards, answering } \\
\text { questions from worksheets. }\end{array}$ \\
\hline $13: 00-14: 00$ & Lunch break \\
\hline $14: 00-14: 45$ & $\begin{array}{l}\text { Review lecture to clear up problem areas from the morning } \\
\text { worksheet }\end{array}$ \\
\hline $14: 45-15: 45$ & Individually-written test \\
\hline $15: 45-16: 30$ & Peer-marking and review of test questions \\
\hline
\end{tabular}

FIGURE 1: Daily structure of the mathematics tutored reassessment programme.

the afternoon session started with a shorter review lecture followed by an individually written test, immediately peermarked by students and followed up with explanations of common problems at a board by tutors. Tutors were also available for one-to-one help at the end of the day. Figure 1 summarises the structure of the mathematics TRP.

Students who obtained final marks of $45 \%-49 \%$ after the first examination qualified for a supplementary examination under normal rules and attendance at the camp was optional for these students. Students with final marks of $40 \%-44 \%$ were allowed to write the supplementary examination provided that they attended the entire TRP. Accommodation at university residences was provided for students who needed accommodation. Funding grants allowed any student to attend without paying fees for tuition or accommodation.

\section{Considerations for the design of the tutored reassessment programme}

The TRP was designed with a rather different perspective on student success, which will be described below. In addition, because this study uses the same impact theory used by outside evaluators in evaluating the July 2014 TRP, this impact theory will be described. Finally, I describe the five theory-based design principles that emerged from reflecting on the weaknesses and successes of the two pilot studies in June 2013 and January 2014.

This study has viewed student success as something broader than simply passing or graduating from a particular course, which according to Harper (2012) is the dominant view in higher education literature. There are many definitions of student success, reflecting different theoretical perspectives on education and giving rise to different types of questions. The view of student success adopted by this project is closer to that of Allie et al. (2009) who take a strong participatory position. They define success as the demonstration of the ability to use the relevant discourse to be able to participate in a workplace community'. In the context of first year mathematics for engineering students, we could consider a 'workplace community' to consist of other courses students take in which they need to use the discourse of mathematics. This definition of success would favour the inclusion of activities that give students practice in their ability to use 
the discourse of first year mathematics and their ability to participate in a community where there are shared goals.

In these first year mathematics courses, there are essential skills and practices that students are expected to 'pick up' by the time they pass the course, such as communicating in a style that is recognised as mathematics, having a confidence to tackle problems and ask useful questions to help to make progress when solving a problem and reflecting on an answer to see if it is feasible. These are unwritten outcomes. However, given the ease with which students can look up information or make complex calculations using technology, the unwritten outcomes are arguably more important than the course outline as defined by the faculty handbook entry, which simply lists topics, for example 'Curve sketching. Applications of the mean value theorem. Rates of change and optimization involving functions of a single variable' (Faculty of Engineering and the Built Environment, 2015, pp. 149-150).

Furthermore, rather than focus on proficiency in mathematics alone, the design of this intervention aimed to address all three areas of under-preparedness identified by Matoti (2010) as impediments to student success. These are: academic under-preparedness (proficiency in English and basic mathematics, effective study skills), cultural under-preparedness (fitting into the dominant culture of the university) and emotional under-preparedness (self-efficacy and self-regulation). The programme addressed these issues by selecting a diverse group of tutors, by having the majority of the students living together in residence and by providing opportunities for students to improve their self-efficacy by experiencing success in answering questions posed by tutors and peers in the whiteboard sessions and in the individual tests. Additional worksheets were made available on a website so that students could practice in the evenings and in the days between the end of the camp and the examination.

\section{Impact theory}

The impact theory of the intervention is the same as for a similar intervention in January 2014 that was externally evaluated and is depicted in Figure 2 (Chapman, 2014). The intervention is intended to increase students' subject knowledge and application skills, improve their attitude towards learning and increase their confidence in their ability to persist in engineering. As a result, a higher pass rate for the compulsory service course should be attained and, ultimately, higher numbers of students should graduate.

\section{Five theory-based design principles}

With the above considerations and theories in mind, the design team reflected on the weaknesses and success of two pilot studies in June 2013 and January 2014 and five theorybased principles for the TRP emerged from this reflection. A pluralistic theoretical framework (Sfard, 1998) acknowledges that education theories are not mutually exclusive and a learning programme designer can simultaneously use multiple educational theories. The principles are outlined below.

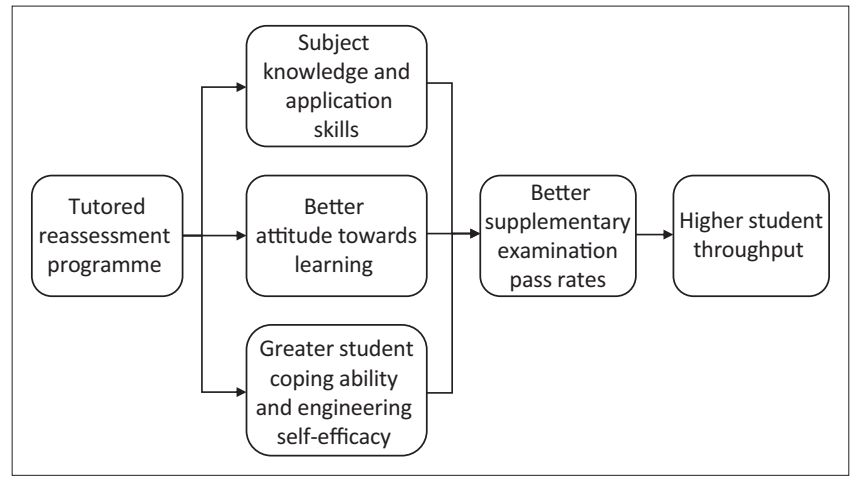

Source: Adapted from Chapman, S. (2014). Tutored supplementary examination revision programmes: An evaluation of the "Supp. Camp" model. Cape Town: The Institute of programmes: An evaluation of the "Supp. Camp"
Monitoring and Evaluation, University of Cape Town.

FIGURE 2: Impact theory of the tutored reassessment programme model.

\section{Principle 1: Transition into university as an issue of identity}

The adjustment to university has been likened to an unavoidable 'rite of passage' (Clark \& Lovric, 2008; Palmer, O'Kane \& Owens, 2009) that is inherently challenging. However, Hernandez-Martinez et al. (2011) found that this time is also viewed by students as an opportunity for growth and to test out new identities. The students attending the programme were high achievers in high school mathematics but had failed university mathematics. The idea that students were seeking opportunities to grow inspired the belief that they would be willing to sacrifice part of their vacation time to attend an intense revision programme and participate actively in it.

\section{Principle 2: Consider students' human needs}

In his humanistic theory of learning, the psychologist Abraham Maslow described a hierarchy of human needs leading to the need for 'self-actualisation', a state of becoming what you have the potential to be (Maslow, 1970). The TRP design ensured that the basic human needs for food and shelter were met by offering university accommodation with meals to all students. Three activities provided students with opportunities to have some control over their learning and to feel a sense of belonging. In the whiteboard tutorials, working in groups was encouraged but students could choose to work independently. After test reviews, there was opportunity for one-to-one consultation with tutors. When working alone outside of contact sessions, students could engage with a tutor or peers in online spaces where resources were shared. The need for self-esteem was addressed by a positive and respectful approach by tutors and by providing the opportunity for students to develop peer relations in the interactive whiteboard sessions.

\section{Principle 3: Students have different levels of actual and potential development}

Lev Vygotsky's Social Constructivism theory claims that students need the guidance of a teacher or collaboration with peers to reach new levels of actual development, where they can solve problems independently (Vygotsky, 
1978). The whiteboard tutorials provided the guidance and collaboration opportunities to allow for this development. In order to maximise the zone of potential development for students during the whiteboard tutorials, the review lectures served as refreshers for students and gave the group a shared experience on which to draw as they worked through the whiteboard tutorials. The safe space of the lectures kept students from being too far from their comfort zone that they were unable to function in the whiteboard tutorials, which may have occurred if students attempted the whiteboard tutorials without the review lecture.

\section{Principle 4: Use both acquisitionist and participationist approaches}

An acquisitionist approach considers learning as a process of gaining knowledge whereas a participationist approach takes the view of learning as a process of becoming able to do something that could be recognised by a community (Sfard, 1998). This principle recognises that students are transitioning from school where an acquisitionist approach to learning is dominant. While the examination structure for these mathematics courses is clearly based on testing whether students have acquired the knowledge outlined in the course syllabus, the TRP also aimed to develop mathematical behaviour, such as laying out work in an orderly way, using questioning to stimulate ideas when stuck, and having tenacity when feeling challenged. The interaction with tutors in all the activities was the primary way in which mathematical behaviour was developed; hence, it was important to select mathematically strong tutors who understood, modelled and encouraged good mathematical behaviour.

Feedback from students in pilot studies suggested that input in the form of a review lecture boosted engagement with the interactive whiteboard tutorials. It was also stressed that students would also have to spend time independently reviewing the coursework from the semester as the review camp would not be able to cover all sub-topics. Students unable to make progress independently would have access to peers and online resources (such as review lectures) from which knowledge could be acquired if they were staying in residence. Formative assessment with many opportunities for practice and feedback was based on the acquisitionist idea of gaining knowledge. Despite reservations regarding the limitations of examinations, the design incorporated practice time for students to experience examination-like conditions.

\section{Principle 5: Quality assurance of success}

This principle followed from the particular perspective on success adopted by the TRP designers. Although the main goal of students attending the TRP would be to pass, it would be of little benefit if students achieved a pass but then failed the subsequent mathematics course. The selection and delivery of lecture and tutorial material aimed to give students adequate preparation to enhance chances of success in the subsequent course. Keeping the examination paper unseen by all the tutors and worksheet developers eliminated any possibility of teaching to the test that may lead to an inflated pass rate. The external examination process used in the normal course examination was followed and the final course mark was determined by replacing the original examination result with the newly obtained examination result. A class mark still contributed to the final course mark.

\section{Methodology}

The methodology of a case study matches a 'situational perspective' (Case \& Light, 2011) rather than hypothesisdriven research looking for cause and effect relationships. The purpose is to gain insight into the mathematics tutored reassessment programme for first year undergraduate university engineering students rather than making statistical generalisations. Data were obtained through three data sources: students' responses to an online questionnaire, individual interviews with students and tutors and an analysis of the pass rates of students who did and did not attend the programme. The three data sources triangulated the emerging data.

The online questionnaire was developed in collaboration with the experienced lecturer who gave the review lectures and observed some whiteboard and test marking sessions. Students were asked to rate the different components of the programme and the resources and to answer 'yes', 'no' or 'unsure' to the following questions: 'Do you feel the TRP helped you gain confidence? Did you make new friends at the TRP? Did you consider changing out of Engineering when you got your results? Do you think that explaining work to others helps you understand? Would you have attended if you had to pay R500 for tuition?' Students could also add free response comments to these questions, as well as to the question 'What would you change about your TRP experience?'

Interviews were semi-structured and followed an interview schedule of potential questions to ensure that each interview spanned the same topics (see Appendix 1). The questions were peer-reviewed by two educational researchers. Audio recordings of the interviews were used to expand research notes taken during the interviews and to transcribe selected quotes. The interview questions asked students about their attitudes to learning, how they coped with their studies and their views on becoming an engineer. The online questionnaire results and interview summaries were discussed with the experienced lecturer who gave the review lectures and consensus was reached on the interpretation of the results as reported here.

Linking to the impact theory in Figure 1, the questionnaire and interviews probed changes in students' attitudes towards learning, their coping abilities and their beliefs that they could become engineers, while the pass rates provided an indication of students' subject knowledge and application skills. 


\section{Ethical considerations}

Ethical clearance was obtained from the faculty-based research ethics committee at the participating university. Participants were informed via consent forms that the purpose of this research was to evaluate the ways in which tutored supplementary examinations can help improve student success, that their identities would be kept anonymous, that their participation was voluntary and neither participation nor non-participation would affect any of their course results and that they could withdraw form from the study at any time. The researcher in this study (the author) was not involved in any assessment of participating students that contributed towards course results.

\section{Findings and discussions Questionnaire and interviews data}

Interviews with students who attended the TRP indicated that attending the camp increased the students' commitment and hours of preparation for the examination, particularly for students who stayed in residence and were able to continue conversations through meal times:

Student T: I definitely spent more hours studying [at residence] than [I would have] at home. We were talking maths in the dining room, at night...

Student L: I wouldn't have worked so much if I was staying at home.

Providing an environment conducive to learning links to principle 2 (Consider students' human needs) and appears to have enabled greater time on task for those staying in residence. Working in the intense way described by these students may help students to establish (or re-establish) an identity as a university student who can handle a challenge, a quality linked to principle 1 (Transition into university as an issue of identity).

The daily programme of the TRP was unanimously praised by the students and tutors who were interviewed, for example:

Student K: The structure was perfect. I wouldn't change a thing.

Many responses to the online question 'What would you change about your TRP experience?' showed high levels of satisfaction with the programme. For example:

[Change] nothing. [I]t was well coordinated.

Perhaps an extra day for consolidation would have been helpful, and maybe test questions could be a little tougher. ... Other than that it was genuinely a wonderful experience.

The two-hour morning lectures were felt by a tutor to be too long but students did not comment negatively about this:

Tutor M: Many students said the lectures were too long.

Tutor N: The lectures went overtime, sometimes by quite a bit. The students didn't seem to mind.

Student T: We had time in lectures to try out problems. [The lectures were] very valuable.
The review lecture helped students to feel less daunted in the whiteboard tutorials and to make effective use of the whiteboard tutorial time:

Student L: Kenny's lectures were brilliant. When we started on the tutorial questions, we knew what was going on.

Tutor N: The students really worked well when they came in after the lecture, surprisingly well, really. I expected that they would want a break, but they didn't.

If there were unresolved problems by the end of the whiteboard tutorials, students valued the time to address misconceptions or knowledge gaps during the review lecture prior to the test:

Student K: The chance for clarification in the afternoon is especially useful if the section is tough or tricky.

Student T: In the afternoon lecture... things clicked.

The variation in satisfaction with the timing of the lecture relates to principle 3 (Students have different levels of actual and potential development). Catering for a diverse range of needs is a challenge in lectures. Online quizzes were suggested by a tutor as a way to keep more advanced students busy during sections of lectures on topics they were confident in. Students liked the test as a way to rate their performance:

Student K: The structure was perfect. I wouldn't change a thing.

When asked to rate the different activities in the programme, 22 out of 29 (76\%) students rated the lectures as 'excellent', 4 as 'okay' and 3 said they did not attend the lectures. None rated the lectures as unhelpful. Principle 4 (Use both acquisitionist and participationist approaches) acknowledges the acquisitionist perspective that is dominant in school and in the way the course is assessed. Students' high levels of satisfaction with lectures may reflect the dominance of an acquisitionist perspective in most students; however, as the following quote shows, the influence of the participationist approach in the design appears to have helped at least one student:

During the semester I would try homework problems at home but often I couldn't do them. ... I'd feel overwhelmed and think 'everyone else seems to know what's going on. I'm so lost, I can't do this'. But now I can! I was working alone one night in the boot camp, trying [a problem] and not getting [it] but then I thought, 'No! I CAN do this,' and I stuck with the problem and thought, 'what am I trying to do? What is the next step?' and ... I solved it! (Student K)

The behaviour of the tutors during the tutorials - questioning to find a way forward when students are stuck, correcting notation use - appears to have provided a model for how to make progress with problems, showing students how to behave mathematically.

The TRP was very successful in building students' confidence and self-efficacy regarding their ability to complete challenging problems, with 35 out of $39(90 \%)$ students in the January 2015 online survey and all 8 out of the $8(100 \%)$ students in the July 2014 survey answering yes to the question 'Do you feel the TRP helped you gain confidence?'. 
TABLE 1: Final results after the July 2014 mathematics tutored reassessment programme.

\begin{tabular}{llcc}
\hline Qualifying mark range (\%) & Attendance at tutored sessions & $\begin{array}{c}\text { Number of students with passing } \\
\text { final marks }\end{array}$ & $\begin{array}{c}\text { Number of students with failing } \\
\text { final marks }\end{array}$ \\
\hline $40-44$ & Compulsory & 12 & 5 \\
$45-49$ & Optional (total numbers) & 15 & 71 \\
$45-49$ & Optional, attended & 3 & 63 \\
$45-49$ & Optional, did not attend & 11 & 2 \\
$45-49$ & Optional, partly attended & 1 & 6 \\
\hline
\end{tabular}

TABLE 2: Final results after the January 2015 mathematics tutored reassessment programme.

\begin{tabular}{llcc}
\hline Qualifying mark range (\%) & Attendance at tutored sessions & $\begin{array}{c}\text { Number of students with passing } \\
\text { final marks }\end{array}$ & $\begin{array}{c}\text { Number of students with failing } \\
\text { final marks }\end{array}$ \\
\hline $40-44$ & Compulsory & 18 & 10 \\
$45-49$ & Optional (total numbers) & 17 & 64 \\
$45-49$ & Optional, attended & 8 & 55 \\
$45-49$ & Optional, did not attend & 7 & 4 \\
$45-49$ & Optional, partly attended & 2 & 87 \\
\hline
\end{tabular}

\section{Pass rates from the July 2014 mathematics TRP}

A total of 27 out of 41 students with qualifying marks of $40 \%-49 \%$ passed, giving an overall pass rate of $66 \%$. Students who attended the full camp had a pass rate of $68 \%$; students who did not attend had a pass rate of $65 \%$. The results for students who attended can be further broken down into those with lower qualifying marks of $40 \%-44 \%$, for whom attendance was compulsory, and those with qualifying marks of $45 \%-49 \%$, for whom attendance was optional.

Surprisingly, the highest pass rate of $71 \%$ came from the 17 students with the lowest qualifying marks of $40 \%-44 \%$. The 12 students in this group who passed would not have been allowed to write the supplementary examination if they did not fully attend the TRP.

Of the 24 students with qualifying marks of $45 \%-49 \%$, $15(63 \%)$ passed (3 attended, 1 partly attended, 11 did not attend) and 9 failed ( 2 attended, 1 partly attended, 6 did not attend). These results are summarised in Table 1.

\section{Pass rates from the January 2015 mathematics TRP}

Compared to July 2014, the January 2015 mathematics TRP had a higher number of students qualifying (59 vs 41) as well as a greater percentage of students attending ( $47 \%$ vs $39 \%)$. The longer time between the release of marks and the supplementary examination in January compared to July may account for the increase in the percentage of students attending, as students living outside of Cape Town had more time to make travel plans.

A total of 35 out of 59 students with qualifying marks of $40 \%-49 \%$ passed, giving an overall pass rate of $59 \%$. Unlike the July camp, students who did not attend the full camp had a pass rate substantially lower than those who did attend (47\% in January 2015 and 65\% in July 2014). The best pass rate was for students with the higher qualifying marks who did attend $(67 \%)$, closely followed by students with qualifying marks of $40 \%-44 \%$, for whom attendance was compulsory.
However, the combined pass rate for students in the $45 \%-49 \%$ qualifying range was only $55 \%$, compared with the $64 \%$ pass rate for students in the $40 \%-44 \%$ qualifying range.

Students who did not attend the TRP but still wrote the examination only had a $47 \%$ pass rate. The difficulty of studying in isolation during a time when families are on holiday may have been a significant factor impacting on these results. The results in Table 2 suggest that there is an advantage for students who attended the TRP.

\section{Financial implications}

For this case study, the cost of tuition and residence was covered by a grant to improve graduation rates of engineering students. Requiring students to pay for this intervention could impact students both positively (by increasing the motivation to pass) and negatively (by adding pressure and expense to vulnerable students). Ways of incorporating the cost of residence during vacation periods into annual residence fees are worth researching further, particularly as the goal of increased participation in higher education is likely to increase the need for financial support for students. In the online survey for the January 2015 students, 56\% (22 students) said they would still have attended if they had to pay R500 for tuition, while 13\% (5 students) said they would not and 31\% (12 students) were unsure. For the July 2014 students, the responses were similarly split with 3, 2 and 3 students answering yes, no and unsure, respectively.

\section{Conclusions}

From a perspective of improving throughput rates in engineering degrees, the tutored reassessment programme (TRP) for first year mathematics was successful because it increased the number of students obtaining credits for first year mathematics courses without spending an additional semester and more course fees on repeating the course. However, 16 students in the first semester and 33 students in the second semester failed with marks below the qualifying range of $40 \%-49 \%$ and were ineligible to write 
the supplementary examination. Given that if students fail, it is most likely to occur in their first year of study and that the adjustment to university is especially difficult in a student's first semester, it is possible that students with final marks lower than $40 \%$ might be able to improve to the required achievement level with the intense revision afforded by the review camp.

In this case study, lower qualification marks did not correspond with lower chances of passing after participating in the TRP. This raises the question of what to choose as the qualification level. For example, if the qualification level was 35\%, 11 more students would have qualified for the July 2014 TRP and 20 more would have qualified for the January 2015 TRP. Before expanding the intake range, however, it would be useful to know the success rate of TRP students in future courses. There is limited value to helping students to pass one course only for them to fail subsequent courses.

Future studies could explore the effects of giving a computermarked entrance test to the TRP to students who do not automatically qualify for a supplementary examination. An entrance test would allow students to demonstrate that they had learnt from their mistakes and completed some selfstudy after the examination, as well as to filter out students who were taking a chance on passing the examination without doing proper preparation.

A limitation of the TRP is that it is not possible to cover all topics of a 12-13 week course in five days. The selection of examples and topics to include in the review camp was based on judgments made by the TRP staff and senior tutors, none of whom saw the examination prior to students writing. Naturally, the questions used in the TRP lectures, tutorials and tests would not have covered the scope of all the work in the course and students were advised to review their course tutorials, notes and test papers in addition to the TRP questions.

This case study showed that students' chances of passing are enhanced if they are given necessary academic support. A concern that future studies should investigate is whether students who are successful in the TRP manage to succeed in future courses. It would be doing students a disservice if helping them to pass first year mathematics though a TRP only prolonged their stay at university before facing exclusion in later years due to not coping with further mathematics courses. The urgency of the need to graduate more engineers and the research showing that adjusting to university is most difficult in a student's first year, especially for first-generation students (Pym \& Paxton, 2013), suggest that an intervention such as the TRP is worth pursuing.

\section{Acknowledgements}

I would like to thank Sue Clegg and Moragh Paxton for mentoring me while developing this article and the Centre for Higher Education Development at the University of Cape Town for supporting the mentorship and providing funding to attend a conference where helpful feedback was obtained on a related presentation. I am also grateful to Kenny Rafel and the tutors and students who participated in this research.

This publication is based on research that has been supported in part by the University of Cape Town's Research Committee (URC).

\section{Competing interests}

The author declares that she has no financial or personal relationships that may have inappropriately influenced her in writing this article.

\section{References}

Allie, S., Armien, M.N., Burgoyne, N., Case, J.M., Collier-Reed, B., Craig, T.S., et al. (2009). Learning as acquiring a discursive identity through participation in a community: Improving student learning in engineering education. European Journal of Engineering Education, 34, 359-367. http://dx.doi. org/10.1080/03043790902989457

Case, J.M., Heydenrych, H., Kotta, L., Marshall, D., McKenna, S., \& Williams, K. (2015). From contradictions to complementarities: A social realist analysis of the evolution of academic development within a department. Studies in Higher Education. http://dx.doi.org/10.1080/03075079.2015.1045479

Case, J.M., \& Light, G. (2011). Emerging research methodologies in engineering education research. Journal of Engineering Education, 100(1), 186-210. http:// dx.doi.org/10.1002/j.2168-9830.2011.tb00008.x

Case, J.M., Von Blottnitz, H., Fraser, D.M., Heydenrych, H., \& Petersen, J. (2013). Thinking and practising curriculum: A new first year course in chemical engineering at UCT. In B. Collier-Reed (Ed.), Proceedings of the 2nd Biennial Conference of the South African Society for Engineering Education (pp. 29-38). Available from http://www.sasee.org.za/cms/wp-content/uploads/2014/06/4.-Thinking-andpractising-curriculum-A-new-first-year-course-in-chemical-engineering-at-UCT. practis

Chapman, S. (2014). Tutored supplementary examination revision programmes: An evaluation of the "Supp. Camp" model. Cape Town: The Institute of Monitoring and Evaluation, University of Cape Town.

Clark, M., \& Lovric, M. (2008). Suggestion for a theoretical model for secondarytertiary transition in mathematics. Mathematics Education Research Journal, 20(2), 25-37. http://dx.doi.org/10.1007/BF03217475

Council on Higher Education. (2013). A proposal for undergraduate curriculum reform in South Africa: The case for a flexible curriculum structure. Pretoria: CHE. Available from www.che.ac.za/sites/default/files/publications/Full_ Report.pdf

Deiaco, E., Hughes, A., \& McKelvey, M. (2012). Universities as strategic actors in the knowledge economy. Cambridge Journal of Economics, 36, 525-541. http:// dx.doi.org/10.1093/cje/bes024

Faculty of Engineering and the Built Environment. (2015). Undergraduate handbook. Cape Town: University of Cape Town. Available from http://www. uct.ac.za/downloads/uct.ac.za/apply/handbooks/Handbook\%207A\%20EBE\%20 Undergraduate\%20Studies2015.pdf

Harper, S.R. (2012). Black male student success in higher education: A report from the National Black Male College Achievement Study. Philadelphia, PA: University of Pennsylvania, Center for the Study of Race and Equity in Education. Available from http://works.bepress.com/cgi/viewcontent.cgi?article=1049\&context=shar from

$$
\text { per }
$$

Hernandez-Martinez, P., Williams, J., Black, L., Davis, P., Pampaka, M., \& Wake, G. (2011). Students' views on their transition from school to college: Rethinking 'transition' as an issue of identity. Research in Mathematics Education, 13(2), 119-130. http://dx.doi.org/10.1080/14794802.2011.585824

Heydenrych, H., \& Case, J.M. (in press). Academic development in the mainstream: A case study in an undergraduate engineering programme in South Africa. South African Journal of Higher Education 29(5).

Kuh, G.D., Kinzie, J., Buckley, J.A., Bridges, B.K., \& Hayek, J.C. (2006). What matters to student success: A review of the literature. Commissioned report for the national symposium on postsecondary student success: Spearheading a dialog on student success. Washington, DC: National Postsecondary Education Cooperative.

Maslow, A.H. (1970). Motivation and personality. (3rd edn.). New York, NY: Longman.

Matoti, S.N. (2010). Assessing the level of preparedness, preferences, and fears of first-year science students at the Central University of Technology, Free State. Journal for New Generation Sciences, 8(1), 135-156.

Palmer, M., O'Kane, P., \& Owens, M. (2009). Betwixt spaces: Student accounts of turning point experiences in the first-year transition. Studies in Higher Education, 34(1), 37-54. http://dx.doi.org/10.1080/03075070802601929 
Pym, J., \& Paxton, M. (Eds.). (2013). Surfacing possibilities: What it means to work with first-generation higher education students. Champaign, IL: Common Ground with first-generation higher education
Publishing, World University Forum.

Race, P. (2014). Making learning happen: A guide for post-compulsory education. (3rd edn.). London: Sage Publications.

Sfard, A. (1998). On two metaphors for learning and the dangers of choosing just one. Educational Researcher, 27(2), 4-13. http://dx.doi.org/10.3102/ $0013189 \times 027002004$
Tinto, V. (2012). Enhancing student success: Taking the classroom success seriously. The International Journal of the First Year in Higher Education, 3(1), 1-8.

Van Eeden, R., De Beer, M., \& Coetzee, C.H. (2001). Cognitive ability, learning potential, and personality traits as predictors of academic achievement by engineering and other science and technology students. South African Journal of Higher Education 15(1), 171-179. http://dx.doi.org/10.4314/sajhe.v15i1.25392

Vygotsky, L. (1978). Mind in society: The development of higher mental processes. Cambridge, MA: Harvard University Press.

Appendix 1 starts on next page $\rightarrow$ 


\section{Appendix 1}

\section{Tutored reassessment programme (TRP) interview schedule - January 2015}

Welcome student, hand out and explain consent forms, ask if the session may be audio recorded.

Questions seek to explore the potential impact of the TRP on

three areas:

- Students' attitudes to learning.

- How they cope with their studies.

- Their views on becoming an engineer.

\section{Sample questions}

1. What did you think of the structure of the TRP, i.e. the lecture followed by whiteboard tutorial, review lecture, test and test review?

\section{Students' attitudes to learning}

2. Do you use a study group? Did you use one in the first semester, during the TRP and in this semester?

3. How much time did you spend alone preparing for the supplementary exam?

4. Have you changed your approach to learning this semester compared with last semester? If there is a difference, to what extent do you think the TRP influenced the change?

\section{How students cope with their studies}

5. What does it mean to you to be successful in a course?

6. How stressful (on a scale of 0-5) was the first semester, the first semester exam, the TRP, the supplementary exam and this semester so far?

7. What do you find helps you to cope with your studies? What is unhelpful or works against you coping with your studies?

\section{Students' views on becoming an engineer}

8. How sure were you at the start of the year that you would qualify with an engineering degree?

9. Did that change after hearing your first semester results?

10. Did that change (again) after the TRP?

11. What do you think it takes to graduate with an engineering degree (besides passing all courses)?

12. Would you complete your engineering degree even if you didn't want to work as an engineer? 